\title{
O CONSENTIMENTO DO OFENDIDO NO DIREITO PENAL
}

\author{
JUAREZ ESTEVAM XAVIER TAVARES
}

(Auxiliar de Ensino de Direito Penal.)

\section{§ 1. Introdução.}

O consentimento do ofendido é freqüentemente mencionado, em Direito Penal, entre as causas de exclusão da antijuridicidade.

Na verdade, essa colocação só veio a ter importância para os penalistas, como enquadramento dogmático, a partir do comêço do século. (') Estruturado o direito punitivo sôbre o critério das normas públicas, entendia-se não se poder excluí-lo de aplicação pela vontade dos particulares. Essa foi a posição da escola histórica, bem como do jusnaturalismo. $\left({ }^{2}\right)$ Era irrelevante para a caracterização do crime a existência ou inexistência do assentimento do titular do bem, quanto ao perigo e à lesão. Superado depois êsse artificialismo e adaptando-se o Direito à realidade social que Ihe serve de substrato, pôde-se, gradativamente, reconhecer à convenção privada o caráter justificante.

Contudo, tendo em vista a moderna teoria do tipo que, por si só, explica suficientemente a não-punibilidade de uma série de fatos, como as intervenções médico-cirúrgicas, sem necessidade de um juízo sôbre a sua ilicitude, o consentimento justificante ainda é referido pela maioria da doutrina, se bem que condicionado a casos raros, em que o bem jurídico ameaçado seja submetido em geral e em particular à disposição privada. $\left({ }^{3}\right)$

Como assinala SAUER, frente às demais causas descriminantes, "aparece o consentimento, como sintoma e como figura auxiliar, nem como a única, nem como a melhor". $\left({ }^{4}\right)$

( 1) Cf. JIMENEZ DE ASUA, L., Tratado de Derecho Penal, Buenos Aires 1961, vol. IV, p. 574.

(2) Cf. EDUARDO CORREIA, Direito Criminal, Coimbra 1965, vol. II, p. 23 e ANIBAL BRU. NO, Direito Penal, Rio 1959, vol. II, p. 17.

(3) Cf. MAURACH, R., Tratado de Derecho Penal, trad. J. CORDOBA RODA, Barcelona 1962, vol. I, p. 404.

(4) Cf. SAUER, W., Allgemeine Strafrechtslehre, Berlim, 1955, 3. Auflage, p. 135. 


\section{§ 2. Histórico.}

A origem do consentimento como descriminante parece encontrar-se na velha e repetida frase romana "volenti non fit injuria" ou "nulla injuria est, quae in volentem fiat". $\left(^{5}\right)$

Injuria seria a lesão intencional da pessoa, em seu corpo, sua honra e situação jurídica. $\left(^{6}\right)$ O consentimento da vítima excluiria a injuria, embora, segundo pondera JIMENEZ DE ASUA, o homicídio, constituindo crime contra o Estado e a comunidade, não se estimasse nessa definição, submetendo-se seu autor às consequiências penais. $\left({ }^{7}\right)$

O texto romano, entretanto, não passou de constituir, apenas, significação jurídica limitada, não podendo ser apreciado em sentido geral. $\left({ }^{8}\right)$

\section{§ 3. Legislação Comparada.}

Os códigos geralmente não dispõem expressamente a respeito de consentimento e de seus efeitos. Alguns, entre os quais o austríaco de $1852(\S 4)$, que sofreram a influência da Constitutio Theresiana e da filosofia do iluminismo de WOLFF, o proíbem.

Na Alemanha, através da lei de 26 de maio de 1933, introduziu-se no Código de 1871, o § 226a, no qual se afirma que "aquêle que produz uma lesão corporal com o consentimento do ofendido, só age antijurìdicamente, se o fato, apesar do consentimento, atenta contra os bons costumes".

Fórmula mais expressa e geral contém o Código Italiano de 1930, no seu artigo 50, segundo o qual "não é punível quem ofende ou põe em perigo um direito, com consentimento da pessoa que dêle pode vàlidamente dispor".

$\mathrm{Na}$ Inglaterra e nos Estados Unidos, em virtude da própria essência do common law, de feição individualista, o consentimento do ofendido tem larga aplicação, que se dá sempre em que o dano privado se refira a direito alienável. $\left({ }^{9}\right)$

Entre os códigos latino-americanos, norma geral se encontra no do Uruguai, de 1933, que no artigo 44 dispõe: "Não é punível a

( 5) Cf. Digesto 47, 10, 1. §5.

(6) Cf. MOMMSEN, TH., Roemisches Strafrechis, p. 748, apud JIMENEZ DE ASUA, cb. cit., p. 574.

( 7) Cf. JIMENEZ DE ASUA, ob. cit., loc. cit.

( 8) Cf. MAURACH, ob. cit., loc. cit.

(9) Cf. JIMENEZ DE ASUA, ob. cit., p. 576. 
lesão causada com o consentimento do paciente, salvo se ela tiver por objeto subtraí-lo ao cumprimento de uma lei ou produzir dano a outrem". Os demais estatutos apreciam mais o consentimento como causa de ausência de tipicidade. $\left({ }^{10}\right)$

No Brasil, os códigos anteriores eram omissos sôbre assunto, o mesmo acontecendo com o vigente. O projeto ALCÂNTARA MACHADO, porém, consignava no seu artigo 14, n. ${ }^{\circ} \mathrm{I}$, que: "Não será também punível aquêle que praticar ação ou omissão: I - com o consentimento de quem possa vàlidamente dispor do direito violado ou ameaçado." Êsse dispositivo foi suprimido pela comissão revisora porque, na opinião de NELSON HUNGRIA, "era evidentemente supérfluo". ( $\left.{ }^{11}\right)$

\section{$\S$ 4. Âmbito de Aplicação.}

A justificativa do consentimento só funciona onde o bem ameaçado se inclua entre os denominados bens disponíveis. Aqui se fixa um dos mais árduos problemas da matéria, que mesmo na atualidade não recebeu solução satisfatória, qual seja, a de estabelecer quais bens seriam considerados disponíveis e em que base se determinaria essa característica.

Na época das luzes, FEUERBACH, GROLMAN, HÄLSCHNER, entre outros, partindo do princípio de que o injusto é lesão de direitos subjetivos, já distinguiam entre direitos alienáveis e inalienáveis, para admitir o consentimento nos primeiros, como excludente do crime. $\left({ }^{12}\right)$ Modernamente, suporta-se a matéria em dois aspectos: um em relação ao amparo dos bens jurídicos e outro conforme a proteção que se dê aos valôres ético-sociais elementares, manifestados no respeito àqueles bens. Assim, em primeiro lugar, se faz necessário distinguir-se entre crimes contra bens do indivíduo e contra bens da coletividade. Nestes últimos torna-se impossível o consentimento, porquanto a proteção se exerce sôbre valôres estatais ou supra-estatais, imprescindíveis à estabilidade social e insuscetíveis de renúncia, tal como ocorre nos ataques à administração pública, em detrimento à integridade do Estado, à incolumidade de um número indeterminado de pessoas ou nos delitos monetários. (13) Também se inclui nesta categoria uma série de fatos localizados na chamada zona de fronteira, em que, a par da lesão social, se produz lesão individual, bem como que sòmente se manifestam contra a sociedade através de

(10) Cf. J!MENEZ DE ASUA, ob. cit., p. 577.

(11) Cf. NELSON hUNGRIA, Comentários ao Código Penal, Rio 1968, Vol. 1, tomo 11, p. 268/9.

(12) Cf. MEZGer, E., Tratado de Derecho Penal, trad. de ROdRIGUeZ MUNOZ, Madri, 1946, vol. 1, p. 405.

(13) Cf. MAURACH, ob. cit., p. 404. 
atentados a bens pessoais, como nos crimes contra a família, a organização do trabalho, a fé pública, os costumes e o sentimento religioso. ${ }^{(14)}$ É verdade que, na prática, a doutrina se defronta, às vêzes, com certas dificuldades em saber se realmente o consentimento possui validade para excluir a ilicitude do fato. Se em certos casos está patente a sua impossibilidade (v.g. na bigamia), em virtude da clara e aparente prevalência do interêsse social, em outros (como no adultério), as dúvidas salientam-se e parecem conduzir, à primeira vista, a caminho oposto. $\left({ }^{15}\right)$ Essas dificuldades poderão ser evitadas, ao se fazer, como indica MEZGER, em cada caso, a operação diferenciadora, segundo o titular do objeto material seja ou não o mesmo do bem jurídico. $\left({ }^{16}\right)$ O importante é não se confundir o titular do bem jurídico protegido com o titular do objeto material. A classificação em crimes contra a coletividade e crimes contra o indivíduo se funda precisamente na titularidade do bem protegido. Desde que o titular do bem seja o Estado ou a comunidade, não se admite validade ao consenso, ainda que se condicione o direito de agir à iniciativa privada.

Não obstante esteja aclarada a categoria individual do bem ameaçado, torna-se indispensável, em segundo lugar, determinar-se se o titular pode ou não dêle livremente dispor. Essa disponibilidade depende da consciência jurídica de cada época e conforme já propunha VON LISZT deve ser inferida de todo o conjunto das disposições legais e não só das qualificações dos fatos puníveis $\left({ }^{17}\right)$ Para suprir as lacunas, é lícito inclusive socorrer-se das normas do direito costumeiro. $\left({ }^{18}\right)$ Contudo, nesta operação, em qualquer hipótese, convém observar-se, como pondera VON HIPPEL, o sentido e o fim da proteção dos bens jurídicos, tomada por base pelo direito positivo. $\left({ }^{19}\right)$ Se o interêsse privado predomina integralmente, o consentimento exclui a antijuridicidade, em decorrência da qualidade renunciável do bem. Se, de outro modo, os interêsses coletivos prevalecem, subsiste a antijuridicidade, apesar do consenso, por se tratar de bem irrenunciável.

(14) Cf. SCHOENKE-SCHROEDER, Strafgesetzbuch Kommentar, München 1957, 8. Auflage, p. 268.

(15) No direito brasileiro não ocorre extinção do crime, quando o marido consente no adultério da espôsa. O caso é de impedimento de processabilidade. (Cf. ROMÃO C. LACERDA, Comentários ao Código Penal, Rio 1959, vol. VIII, p. 382.)

(16) Cf. MEZGER, ob. cit., p. 405.

(17) Cf. VON LISZT, F., Tratado de Derecho Penal, trad. JIMENEZ DE ASUA, Madri, 1927, vol. II, p. 353 e MEZGER, ob. cit., loc. cit.

(18) Cf. DELOGU, T., Teoria del Consenso dell'Avente Diritto, p. 232, apud J. FREDERICO MARQUES, Trałado de Direiło Penal, S. Paulo 1965, vol. II, p. 144.

(19) Cf. VON HIPPEL, R., Deutsches Strafrecht, vol. II, p. 243, apud JIMENEZ DE ASUA, ob. cit., p. 584 . 
Restam, pois, poucos delitos para a justificava do consentimento. Entre os bens particulares renunciáveis, que podem, portanto, sujeitar-se à sua atuação, há quase unanimidade em mencionar-se a honra, a liberdade pessoal, a integridade corporal, assim como todos os bens jurídicos patrimoniais. $\left({ }^{20}\right)$ Quanto à vida, esta é evidentemente irrenunciável. O consentimento quanto ao homicídio poderá atenuar a culpabilidade, mas jamais refletir-se na caracterização do injusto. É que para o Direito Penal, como bem assevera MAU$\mathrm{RACH}$, é irrelevante a questão de ser a vida um bem do particular ou da comunidade, pois a proteção que a ela se dá é irrenunciável tanto frente às lesões, quanto frente ao perigo. $\left({ }^{21}\right)$

\section{$\S$ 5. Funções: Exclusão do Tipo e Justificativa.}

Além de justificativa, como causa de extinção da antijuridicidade, o consentimento pode ter, para o Direito Penal, mais dois outros significados.

Primeiramente, insere-se êle como elemento indispensável à própria existência do crime. Aqui, a ausência de consentimento exclui o crime, por faltar ao tipo um dos seus elementos essenciais. No Direito brasileiro, exemplos disso aparecem no abôrto consensual, na usura e de certa maneira no rapto consensual.

Em segundo lugar, sua função é de excluir a tipicidade da conduta. Nesta hipótese, o dissenso do titular do bem pertence ao tipo. Havendo o consentimento, não haverá crime, por ausência do tipo, figurando, portanto, situação inversa com a mencionada anteriormente.

Diz-se que o dissenso do ofendido pertence ao tipo, quando o atuar do agente importe em uma ameaça ou aplicação de fôrça $\left({ }^{22}\right)$ ou quando a ação típica esteja vinculada a essa não-concordância. ${ }^{(23}$ ) Citam-se, comumente, como exemplos dêsses casos, os crimes de constrangimento ilegal, seqüestro ou cárcere privado, invasão de domicílio, violação de correspondência ou segrêdo e ainda os delitos sexuais e alguns contra o patrimônio (furto, roubo, etc.).

Todavia, nem só nos delitos citados pode haver a exclusão do tipo, em decorrência do consentimento. Esta sempre ocorrerá em todos os fatos puníveis em que se exija a atuação contra a vontade do titular do bem. Para o caso específico da falsidade documental, por

(20) Cf. MAURACH, ob. cit., p. 406.

(21) Cf. MAURACH, idem, p. 405.

(22) Cf. MAURACH, ob. cit., p. 406.

(23) Cf. MEZGER, ob. cit., p. 406. 
exemplo, WELZEL esclarece que "assim como não há violação possessória com o consentimento do possuidor na subtração, não há falsificação de documento, se o declarante deixou apor seu nome, por meio de um terceiro, sob o documento". $\left({ }^{24}\right)$ Também nesse exato sentido se manifesta BAUMANN de que "inexiste falsidade documental se aquêle, de quem o documento parece provir, consentiu na assinatura em seu nome". ${ }^{25}$ )

A distinção entre o consentimento como excludente de ilicitude e como causa de ausência de tipicidade, possui importância no setor das fases de realização do crime. Se $\circ$ autor desconhece o consentimento do titular, em se tratando de justificativa, resulta irrelevante, respondendo êle por crime consumado. Todavia, na hipótese de ausência de tipicidade, o desconhecimento acêrca do consenso dará lugar à tentativa punível. $\left({ }^{26}\right)$ No Brasil, essa solução não colide com a norma do Código Penal que declara impune a tentativa, quando absoluta a impropriedade do objeto ou a inidoneidade do meio. Ao adotar a teoria objetiva temperada, nesse sentido, o legislador pátrio não impediu fôssem tratados pela doutrina, segundo seus próprios fundamentos, os demais casos de tentativa inidônea não compreendidos no referido dispositivo. Os autores brasileiros, todavia, em sua parte mais saliente, opõem-se ao tratamento pretendido pelo texto, invocando a teoria da ausência do tipo (Mangel am Tatbestand), com a qual procuram ver, na hipótese, um fato atípico estranho ao Direito Penal. $\left({ }^{27}\right)$ Hoje, em contrapartida, a tendência é de se apreciar - assunto como tentativa, tendo por base o conceito moderno de situá-la entre as formas de defeito de congruência do tipo. $O$ agente que contava com a produção integral do delito não pôde alcançá-lo por estar ausente uma de suas características típicas, por êle suposta como ocorrente.

\section{$\S$ 6. Fundamentos e Requisitos.}

No que toca ao fundamento da justificativa do consenso, embora persistam as dúvidas e divergências, a doutrina quase assentou vincular-se êle a princípios gerais. Neste ponto variam as opiniões sôbre o princípio a ser aplicado.

Para MEZGER, o consentimento constituir-se-ia no exemplo clássico da exclusão do injusto com base no princípio da ausência do in-

(24) Cf. WELZEL, H., Das Deutsche Strafrecht, Berlim, 1967, 10. Auflage, p. 91.

(25) Cf. BAUMANN, J., Strafrecht, Allgemeiner Teil, Bielefeld 1966, 4. Auflage, p. 307. No direito positivo, encontramos idêntica solução no art. 245, inciso III, do Código Mexicano de 1931.

(26) Cf. MAURACH, ob. cit., p. 406 e infra $§ 7$.

(27) Cf. ANIBAL BRUNO, ob. cit., p. 249 e segs. e NELSON HUNGRIA, ob. cit., p. 102. 
terêsse. Sua verificação só caberia com a pressuposta existência de abandono de interêsse por parte de quem legìtimamente tivesse a faculdade de disposição do bem. $\left({ }^{28}\right) \mathrm{O}$ argumento se funda em que o conteúdo de todo e qualquer injusto representa uma lesão de interêsse. Inexistindo interêsse, assim como apresentando-se um interêsse maior, conseqüentemente desaparece o injusto.

SAUER já o enquadra como manifestação do princípio do interêsse preponderante, segundo o qual uma ação típica é sempre e tão só ajustada ao direito, quando faz prevalecer um interêsse de superior valor, à custa de um bem menor. $\left({ }^{29}\right)$

Mais correta se nos apresenta a posição de MAURACH e WELZEL que o situam entre os casos em que a norma cede, como conseqüência da renúncia do bem jurídico ameaçado, à proteção jurídica. $\left({ }^{30}\right)$ Tôda norma se destina e serve à proteção dos bens jurídicos e também se encontra promulgada para viger em situações normais, não em estados de exceção. Em conseqüência, todos os bens jurídicos merecem o amparo da norma. Essa proteção se faz através de proibições e comandos dirigidos à coletividade e alicerçados em juízos de valor. Entretanto, se por um lado, a norma expressa-se, por motivo de autoridade, em mandatos e têrmos de valoração absoluta, não pode ser tomada em consideração independentemente do substrato de valôres a que deve sua origem e validez, nem tampouco vigorar em todos os conflitos imagináveis. Há ocasiões em que o bem ałacado renuncia à proteção da norma, constituindo uma situação anormal. Essa situação arrasta consigo a norma, fazendo-a retroceder, pois já não interessa a ela proteger o bem, tendo em vista o critério de valor de uma situação normal. $\left({ }^{31}\right)$

Partindo-se dêsse último fundamento, está claro que, para ser possível a renúncia, são necessários alguns requisitos, que valem tanto para o consentimento justificante, como para aquêle tomado como causa de ausência de tipicidade, com a ressalva apenas de que, enquanto para o primeiro, como já vimos, pressuposto indeclinável é que, antes de tudo, o bem jurídico ameaçado se submeta, em geral e em concreto, à disposição privada, $\left({ }^{32}\right)$ para o outro, obrigatório tão sòmente é que a atuação contra a vontade do titular pertença ao tịo. ${ }^{\left({ }^{3}\right)}$ De resto, as condições são idênticas.

\footnotetext{
(28) Cf. MEZGER, ob. cit., p. 397.

(29) Cf. SAUER, ob. cit., p. 135.

(30) Cf. MAURACH, ob. cit., p. 404 e WELZEL, ob. cit., p. 91.

(31) Cf. MAURACH, idem, p. 361.

(32) Cf. supra § 1 e $\S 4$.

(33) Cf. supra $§ 5$.
} 
Assim, primeiramente, junto à renúncia do bem ameaçado, deve estar presente o consentimento acêrca da espécie e forma de ataque que se irá transferir. $\left({ }^{34}\right)$ Esta investigação requer a análise da norma, bem como da figura típica, inclusive para se determinar a titularidade do bem. Se o bem pertence a mais de um titular, é mister o consentimento de ambos. Por outro lado, nem sempre tôdas as formas de ação típica se justificam pela concordância sôbre o perecimento do bem. Elucidador a respeito é o exemplo de MAURACH de que um benévolo camponês pode, talvez, fazer vistas grossas, quando de noite, se the subtraem batatas do campo lavrado; contudo, o consentimento não se estenderá ao fato de que o ladrão tome as batatas, nem sequer na mesma quantidade, do paiol fechado ou dos sótãos pertencentes ao lavrador. $\left({ }^{35}\right)$ Também, no roubo, v.g., o fato não se exclui pelo consentimento dado à subtração do objeto, se não atingiu inclusive a ameaça ou a lesão. $O$ consentimento deve se referir de modo específico à modalidade de ação. Êsse tratamento resulta, em última análise, da adoção no Direito Penal da teoria dos valôres. A missão do direito punitivo, como bem diz WELZEL, não está na proteção pura e simples dos bens jurídicos, mas inclusive no amparo dos elementares valôres ético-sociais da ação. Deve firmar-se a consideração no valor do resultado (Erfolgswert) e no valor do ato (Aktwert). Pune-se, dessa maneira, o homicídio, tanto pela morte efetivamente produzida (desvalor do resultado), como pela ação que tende a produzí-la (desvalor do ato). Só assim será possível assegurar a plena vigência dos valôres positivos ético-sociais dos atos, como o respeito à vida alheia, à saúde, à liberdade, ao patrimônio, etc. $\left({ }^{36}\right)$

Ademais, o consentimento deve ser anterior ao ato desenvolvido pelo agente. $\left({ }^{37}\right)$ Sua verificação posterior só terá eficácia para o Direito Processual Penal, no reconhecimento da renúncia ao direito de queixa, em determinados delitos.

Além disso, ao titular do bem exige-se capacidade para consentir. Essa capacidade será aferida, não pelo Direito Civil, $\left({ }^{38}\right)$ mas com base no próprio Direito Penal. Alguns autores inferiram-na da esfera da imputabilidade: sòmente os imputáveis penalmente poderiam consentir. Hoje, como assevera MEZGER, "essa regularização formal não corresponde à própria natureza das coisas, sendo mais correto decidir-se com base nas circunstâncias e natureza de cada caso con-

(34) Cf. MAURACH, ob. cit., p. 408.

(35) Cf. MAURACH, idem, p. idem.

(36) Cf. WELZEL, ob. cit., p. 1 e segs.

(37) Cf. MAURACH, ob. cit., p. 409; MEZGER, ob. cit., p. 403.

(38) Cf. FREDERICO MARQUES, ob. cit., p. 144, que adere ao princípio do Direito Privado. 
creto, examinando se o lesionado possuía a necessária capacidade de juízo e se o consentimento correspondia à sua verdadeira vontade". $\left({ }^{39}\right)$ Ou melhor, como se expressa MAURACH, o titular do bem deve conhecer suficientemente "a essência e o alcance de sua renúncia" $\left({ }^{40}\right)$. Assim, não haverá consentimento válido, quando obtido por vício de vontade (coação ou êrro).

Quanto à forma, em princípio, requer-se a expressa. Porém, como assinala MAGGIORE, admite-se lugar ao consentimento tácito quando, em virtude das circunstâncias, se torna iniludível a renúncia do titular do bem. $\left({ }^{4}\right)$

Questão duvidosa é a que pesquisa sôbre a possibilidade da delegação ou representação de vontade no consentimento. Sua importância destaca-se nas intervenções médico-cirúrgicas. Sabe-se que de acôrdo com a doutrina tradicional, torna-se imprescindível, nessas atividades, a referência a uma causa de justificação: a ação será típica, porém lícita. Para aquêles que elegem o consentimento como descriminante, como também para os que, vendo nos meios curativos uma forma de exercício regular de um direito, necessitam de sua incidência para legitimar êsse exercício, deve-se conceder solução ao problema, freqüente, de ser válido ao pai representar a vontade de seu filho menor para o efeito de justificar a lesão produzida pela intervenção. MEZGER nega qualquer possibilidade à representação. $\left({ }^{42}\right)$ A opinião correta seria a de se admitir a representação, dentro de certos limites. Isto teria o efeito de suprir as lacunas no sistema jurídico, nos casos em que se necessita de uma justificativa para os tratamentos curativos por parte de pessoas encarregadas de custódia, guarda ou autoridade sôbre menores, doentes ou incapazes. $\left({ }^{43}\right)$ A questão está perdendo, atualmente, o interêsse, ao se justificar a intervenção cirúrgica como ausência de tipicidade. $\left({ }^{44}\right)$ No Brasil, conforme lembra FREDERICO MARQUES, a representação é admitida no abôrto (art. 128, II) e no constrangimento ilegal (art. 146, § 3., n. ${ }^{\circ}$ I). $\left({ }^{45}\right)$

\section{§ 7. Elemento Subjetivo de Justificação.}

Muito mais discutido é o problema ligado aos elementos subjetivos de justificação: se basta para validar o consentimento que ês-

(39) Cf. MEZGER, ob. cit., p. 401.

(40) Cf. MAURACH, ob. cit., p. 409.

(41) Cf. MAGGIORE, G., Trałado do Derecho Penal, Bogotá 1954, trad. de ORTEGA TORRES, p. 437 - vol. 1.

(42) Cf. MEZGER, ob. cit., p. 402.

(43) Cf. MAURACH, ob. cit., p. 409.

(44) Cf. MAURACH, idem, p. 407.

(45) Cf. FREDERICO MARQUES, ob. cit., p. 144, nota n. 16. 
te se verifique apenas objetivamente ou se é necessário, além, o conhecimento do consenso por parte do agente.

Tradicionalmente, duas teorias disputaram a preefrência dos autores a êsse respeito: a teoria do negócio jurídico, de ZITELMANN, também denominada de teoria da declaração, e a teoria da direção da vontade ou teoria da ação jurídica, que agregava a maioria. Pela primeira, conforme ensina EDUARDO CORREIA, "o consentimento do ofendido relevante para o Direito Penal é um negócio jurídico unilateral, uma declaração de vontade dirigida à produção de um resultado jurídico que sendo eficaz possui o efeito de atribuir à parte contrária um direito de ação, aliás revogável a todo o tempo". $\left({ }^{46}\right)$ Como o consentimento é tratado, para ZITELMANN, no quadro dos negócios jurídicos (§§ 182 do BGB), subordina-se aos requisitos dêstes, requerendo, destarte, uma manifestação expressa do titular acêrca do seu conteúdo e de seu alcance. $\left({ }^{47}\right)$ De conformidade com êsse pensamento, só se justificava o fato, se o autor agisse com base em um consentimento por êle conhecido.

Em sentido positivamente oposto, mantinha-se a teoria da direção da vontade, para a qual o consentimento produziria seus efeitos, objetivamente, sem ter em conta o conhecimento do sujeito ativo. $\left({ }^{48}\right)$

A opinião mais convincente, na atualidade, se afirma na conjugação de elementos de ambas as teorias. $\left({ }^{49}\right) \mathrm{Se}$, por um lado, a teoria da direção da vontade possui o mérito de eliminar dessa matéria tôda e qualquer referência ao Direito Civil, tratando-a nos postulados do Direito Penal, por outro, não se pode negar para a justificação a exigência de um consentimento conhecido pelo agente.

Pode acontecer na realidade, que 0 agente desconheça o consentimento objetivamente existente. Nessa hipótese, adotando-se o último critério, responde êle por crime consumado. Alguns, entre os quais MEZGER, opinam, na espécie, pela existência de crime tentado $\left({ }^{50}\right)$, o que não pode prevalecer, mesmo como se preconiza, na forma de crime impossível. Ora, a tentativa decorre de defeito ou falta do tipo objetivo. Há tentativa quando, embora o agente possua a repreesntação e vontade na concretização do tipo, êste não se realiza porque está ausente um dos seus elementos. No caso presente,

(46) EDUARDO CORREIA, ob. cit., p. 21.

(47) Cf. MAURACH, ob. cit., p. 410.

(48) Cf. MEZGER, ob. cit., p. 399.

(49) Cf. BAUMANN, ob. cit., p. 300.

(50) Cf. MEZGER, E., Strafrecht, ein Studienbuch, § 38 II 2, apud EDUARDO CORREIA, ob. cit., p. 28, n. 1. 
não há tentativa porque o tipo objetivo se apresenta sem qualquer desfiguração nos seus elementos. O que está ausente é o conhecimento do agente acêrca da existência de um elemento de justificação, que é o consentimento. Aliás, mesmo para a teoria da direção da vontade não interessa a configuração da tentativa: ou se reconhece o fato justificado na sua ilicitude ou se o pune como crime consumado. $\left(5^{1}\right)$

Diverso, entretanto, é o tratamento quando o agente pressupõe erradamente a existência de um consentimento que na realidade não se apresenta. Já não estamos, aqui, diante de uma causa de exclusão do injusto, mas sim de um êrro de proibição (catalogado, imperfeitamente, no Código brasileiro, como êrro de fato). Se o êrro fôr vencível, pode responder o agente por crime consumado culposo. Se invencível, exclui-se a culpabilidade.

Convém esclarecer, finalmente, que a exigência do conhecimento em relação ao consenso não importa em negar-se a justificativa nos delitos culposos. Nesta série de fatos, o saber refere-se ao consentimento incidente ou sôbre o resultado previsto como possível ou sôbre a ação descuidada que objetivamente encerra uma tendência lesiva. $\left({ }^{52}\right)$

\section{$\S 8$. Ineficácia.}

O direito consuetudinário estabelece que o consentimento não tem eficácia, ainda que se trate de bem renunciável, se o fato atentar contra os bons costumes. Êsse princípio encontra guarida no parágrafo 226a do Código Penal alemão de 1871 e é repetido pela maioria da doutrina.

Entre nós, esclarece ANIBAL BRUNO que, "é preciso que o ato não colida com as normas de cultura - com os costumes e exigências etico-sociais". $\left({ }^{53}\right)$ Essa regra, observe-se, diz respeito à imoralidade do fato, não do consentimento. Êste pode-se assentar em motivos mais do que reprováveis e nem por isso se deve concluir o mesmo em relação ao fato. Significativos exemplos de imoralidade do fato são os citados por SCHOENKE-SCHROEDER, do proprietário que consente no incêndio de um seu objeto com a intenção de fraudar o seguro ou da pessoa que consente na sua mutilação para idêntico

(51) MAX ERNEST MAYER refere-se à tentativa com ausência de antijuridicidade (Cf. nota de RODRIGUEZ MUÑOZ na tradução do Tratado de MEZGER, ob. cit., p. 242).

(52) Cf. MAURACH, ob. cit., p. 236, vol. II; BAUMANN, ob. cit., p. 229; WELZEL, ob. cit., p. 93 e MEZGER, ob. cit., p. 399.

(53) Cf. ANIBAL BRUNO, ob. cit., p. 21. 
fim ou para satisfazer instintos sádicos. $\left({ }^{54}\right)$ É indiferente que o último caso não constitua ilícito penal. O consentimento é ineficaz tão só porque o fato ofende os bons costumes.

\section{§ 9. Consentimento Presumido e Atuação no Interêsse do Ofendido.}

Ao lado do consentimento de que até agora tratamos, figuram também como causa de exclusão do injusto, o consentimento presumido e a atuação no interêsse do ofendido.

Estas causas de justificação foram aventadas pela vez primeira por ZITELMANN $\left({ }^{55}\right)$, recebendo posteriormente $\circ$ estudo de ARDNT e o enquadramento dogmático de MEZGER. Êste último as acolhe para amparar certas situações em que, embora falte o consentimento, a realização da conduta corresponde ao mais urgente interêsse do suposto lesionado. $\left({ }^{56}\right)$

Ambas possuem o mesmo princípio orientador: 0 interêsse do ofendido. MAURACH as diferencia porque, enquanto no consentimento presumido há abandono de interêsse, no outro caso, isto é, na atuação no interêsse do ofendido, o que se dá é a conservação do interêsse. No consentimento presumido a norma cede pela renúncia do bem. Na outra hipótese, identifica-se uma colisão de bens pertencentes a uma mesma pessoa e cuja solução será proporcionada por um terceiro, seguindo um juízo hipotético sôbre a solução que daria o titular do bem, se estivesse naquela situação $\left({ }^{57}\right)$

Segundo essa diferença, os exemplos mais clássicos de consentimento presumido, como o do sujeito que se introduz na casa do vizinho, durante sua ausência, para consertar uma torneira e evitar assim conseqüências mais graves, pertencem à atuação no interêsse do ofendido. Haveria consentimento presumido no caso de correção de filhos alheios.

A antijuridicidade, destarte, se exclui nem só em virtude de um consentimento real, conhecido pelo agente, mas também quando se possa dizer que o lesionado haveria consentido com a atuação, se tivesse tido conhecimento da efetiva situação das coisas. $\left({ }^{58}\right)$ Para determinar-se como seria, realmente, manifestada a vontade do titular do bem, trabalha-se com um juízo hipotético de probabilidade, tendo em vista a racional atitude a ser tomada por êle, diante dos fatos.

(54) Cf. SCHOENKE-SCHROEDER, ob. cit., p. 269.

(55) Cf. ZITELMANN, Ausschluss der Widerrechłlichkeit, Tübingen, 1906, p. 103, apud JIMENEZ DE ASUA, ob. cit., p. 580.

(56) Cf. MEZGER, ob. cit., p. 413.

(57) Cf. MAURACH, ob. cit., p. 413.

(58) Cf. MEZGER, ob. cit., p. 414. 
Se o autor conhecia a vontade oposta do titular, pode o fato ser justificado pelo estado de necessidade. MEZGER, contudo, entende que mesmo assim teria cabida o consentimento presumido, uma vez que a oposição pode ter sua causa em uma interpretação errônea do estado de fato, em cuja hipótese é indubitável que se o houvesse reconhecido, haveria dado o consentimento, $\left({ }^{59}\right)$ Essa posição evidentemente leva muito longe o desdobramento da teoria da direção da vontade, que não deve persistir, sob pena de enfraquecer a proteção que se dá aos bens jurídicos, levada em conta no amparo dos valôres ético-sociais de respeito a êsses bens.

Da mesma forma como o consentimento real, é indispensável também aqui que o sujeito ativo haja presumido a vontade do titular. Não basta que esta vontade se identifique apenas com o atuar objetivo.

\section{$\S 10$. Conclusões.}

Diante do que foi exposto e do que procuramos colocar, tornam-se viáveis as seguintes conclusões:

I) O consentimento do ofendido pode ser admitido como causa de exclusão da antijuridicidade, no Direito Penal, embora tenha lugar em poucos e raros casos.

II). Modernamente, convém dispensar-lhe tratamento legislativo, a fim de se evitar o alargamento das causas supralegais de justificação.

III) Dar-se-á a justificativa em delitos contra o sujeito individual, quando o titular do bem possa dêle livremente dispor. Se, além de bem jurídico pessoal renunciável, a conduta afetar também um bem ou interêsse da coletividade, torna-se impossível o consentimento justificante. Tal, contudo, não vigora para o consentimento como causa de exclusão da tipicidade, que, pela própria estrutura do delito, está vinculado a pressuposto diverso.

IV) Apesar das divergências, a proposição mais correta é a que contempla o consentimento como conseqüência da renúncia do bem jurídico ameaçado à proteção jurídica, estabelecendo-o, portanto, em norma geral de justificação.

V) Só possui eficácia o consentimento dado por agente capaz. Essa capacidade deve ser inferida do caso concreto, independentemente do grau de imputabilidade, bem como das regras do Direito

(59) Cf. MEZGER, ob. cit., p. 416. 
Privado. Afora isso, o consentimento deve-se referir à espécie e forma da ação típica, sendo, sempre, anterior à manifestação de vontade do sujeito ativo.

VI) É possível o consentimento tácito, sòmente quando se torna iniludível, diante das circunstâncias, a renúncia do titular do bem.

VII) A representação da vontade no consentimento, se bem que esteja perdendo o interêsse na atualidade, deve ser admitida para suprir as lacunas no sistema jurídico.

VIII) Na determinação dos elementos subjetivos de justificação, e em virtude de sua exigência na doutrina moderna, não pode ser esquecido o consentimento. Só se justifica o fato, se, além do consentimento objetivo, o agente possuir o conhecimento da sua declaração ou existência. O desconhecimento do agente acêrca do consenso é irrelevante, respondendo êle por crime consumado. Se, entretanto, supõe erradamente a existência do consentimento ausente na realidade, pode ter sua culpabilidade excluída, se o êrro fôr invencível.

IX) Em qualquer caso, não acode a justificativa, se o fato contraria os bons costumes, as normas de cultura ou o substrato dos valôres ético-sociais.

X) Ao lado do consentimento real, são relevantes ainda o consentimento presumido e a atuação no interêsse do ofendido. Estas causas necessitam de um juízo de probabilidade sôbre a vontade suposta do titular do bem. É impossível serem tidas como válidas, se o agente conhecia a vontade oposta do titular. 